\title{
Permissions Limbo: Intellectual Property and Licensing Issues
}

THE WORLD AS WE KNEW IT changed sometime in the early 1990s-maybe a little bit before or maybe a little bit after, but it most definitely changed. Since the advent of the World Wide Web, not only do libraries, archives, and museums have to perform their traditional tasks — collecting, preserving, studying, researching, displaying, and providing access to collections in physical spaces-but there is now an expectation, if not a mandate, to create digital surrogates of the works in institutional collections, especially rare and unique materials, and make them accessible electronically. In addition to making good quality digital copies, institutions must create metadata to facilitate federated and visible Web searching, maintain the newly created digital files on servers, develop and upgrade software programs to obtain and maintain interoperatability, and establish vibrant digital preservation programs that continually check that no bits or bytes are lost and technical formats are migrated as needed. This is a tall and expensive order, especially when most institutions and funding organizations require digitization and Web projects to be self-sustainable. ${ }^{1}$ To accomplish this task, cultural institutions continue to explore different options and opportunities and in many cases have partnered with others, including for-profit companies, to share the new work load and defray the resulting new costs.

Before libraries, archives, and museums can make digital surrogates of rare books and manuscripts and provide access to them, they need to consider the copyright status of the works to be digitized, whether the project can proceed under a legal exception such as fair use ( $\$ 107$ of the United States copyright law), ${ }^{2}$ or reproduction by libraries and archives $(\S 108),{ }^{3}$ or whether permission is needed from the rights holder(s). Rare books and manuscripts have many definitional attributes, but these unique materials are not necessarily always old enough to be

1. Donald J. Waters, "Building on Success, Forging New Ground: The Question of Sustainability," First Monday 9, no. 5 (May 2004), available online at www.firstmonday.org/ISSUES/issue9_5/waters/ (Accessed March 21, 2009).

2. 17 U.S.C. 107.

3. 17 U.S.C. 108. 
in the public domain. Many of these special collections works, especially unpublished materials, are still protected by copyright. ${ }^{4}$

There are six basic questions that, when answered, should lead rights researchers to decisions about the copyright status of a work and a realistic assessment of how easy or difficult it might be to obtain permission to create and distribute the digital copies. Unfortunately, it is easier to ask these questions than it is to answer them. It is also important to note that, when considering legal risks, institutions should consult an attorney to ensure that the analysis of the facts and the applicable law is correct and that the potential consequences of an action are clearly understood by all decision makers.

\section{The Questions}

1. Is the work protected by copyright?

2. Does the proposed use require permission or does it fall under one of the legal exceptions?

3. Are there any other intellectual property concerns such as privacy, publicity, or trademark rights that need to be considered?

4. How many rights holders are there?

5. Does the institution know the rights holder(s) and how to contact them?

6. What rights do you need and for how long?

\section{The Answers}

Many organizations offer intellectual property law workshops ranging from one-hour webinars to single and multiple-day programs with required reading and homework. Countless helpful books and reliable Web resources are available. Some of these resources will focus on a single issue such as fair use or the permission process; others will provide a broader survey of the law and legal decisions. Like anything else, learning about intellectual property takes commitment. Even with extensive training and years of experience, complex situations arise that can reduce grown men and women to tears. One should not despair, however. The law appreciates good faith. Conduct rights research as best as you can and keep a record of the findings and answers, or lack thereof; be sure to note what was done, who was contacted, and when. Remember, many rights questions cannot be answered definitively. Uncertainty is part of the challenge.

4. Determining whether a work is in the public domain or protected by copyright can be frustrating and inconclusive. A useful tool to help with this challenge was developed and is maintained by Peter Hirtle. It is updated annually and sets forth all of the ways in which a work may be characterized for purposes of determining if the work is still protected by law and, if so, what the term of such protection is. See www.copyright.cornell.edu/public_domain/copyrightterm.pdf (Accessed October 14, 2008). 


\section{The Decisions}

At the conclusion of the question and answer process, there are three probable outcomes:

1. The institution has confirmed in writing and with documentation that it has the rights needed to digitize the selected rare book and manuscript materials and distribute them in the authorized media.

2. The institution has determined that it can proceed under a legal exception and has a contemporaneous writing explaining its rationale for this approach. The importance of the contemporaneous writing should not be underestimated or overlooked. Everyone forgets things over time, and recreating the thinking and decisions made years ago by different people can be difficult. The contemporaneous writing may not resolve an infringement claim, but it definitely indicates the institution's good faith and may serve to limit the amount of damages that can be awarded. ${ }^{5}$

3. The institution either accepts or rejects certain legal risks related to making and distributing digital copies of rare books and manuscript materials based on ambiguous or incomplete rights information.

\section{Negotiating Points}

Having determined the copyright status of the works in the collections, and having either obtained permission from the rights holder, or concluded that the proposed use falls within one of the laws' exceptions, or accepted the fact that there may be some legal risk in digitizing the materials because the copyright status of the works is not perfectly clear, the institution now needs to decide how it will proceed with its digitization project(s). Most institutions do not undertake large digitization projects in-house because of equipment needs and staff time demands; rather, the work is frequently outsourced to an independent contractor. While every contract negotiation is different, there are key terms that come up regularly when outsourcing digitization work. For successful results, it is important that the institution has a clear understanding of its goals before entering negotiations. Essential reading for institutional negotiators is "Good Terms-Improving Commercial-Noncommercial Partnerships for Mass Digitization.” This article offers real-life experiences from institutional leaders involved in mass digitization projects and includes "...a mix of specific recommendations, general best practices, and broad statements of principle."'Best of all, the authors provide insights into the motivations and perspectives of both the institutions seeking digitization of their selected materials

5. 17 U.S.C. 504(c)(2).

6. Peter B. Kaufman and Jeff Ubois, "Good Terms-Improving Commercial-Noncommercial Partnerships for Mass Digitization,” D-Lib Magazine 13, no. 11/12 (Nov./ Dec. 2007), available online at www. dlib.org/dlib/november07/kaufman/11kaufman.html (Accessed October 13, 2008). 
and the companies working with them. In negotiations, it is essential for each party to understand and recognize what it brings to the bargain and what the other side wants and offers.

As in any contract negotiation, clarity is essential—say what you mean and mean what you say. Read the contracts over and over again, including the small print, and be sure everyone involved, not just the lawyers, understands them. If there are provisions that are ambiguous or confusing, ask questions, and do not stop asking questions until you have answers you comprehend and can explain to someone else.

Every contract should address the following: price and payment procedures; the right to terminate and what penalties might be incurred as a result; insurance coverage, especially for damage to special collections materials; indemnification of the institution by the contractor for third-party claims arising from breach of contract, including those based on representations and warranties; choice of law; and use of the institution's name and brands. In digitization contracts, there are a number of critical provisions: description of the scope of work including where the digitization work will take place (for example, inside or outside the United States); the service level agreements (SLAs) for technical specifications and formats; who creates and who owns the metadata; deliverables; deadlines; and the manner in which and by whom the special collections materials will be handled. The most important decisions, however, involve who owns the digital files and when that ownership is effective, as well as the terms and conditions under which the contractor and/or institution can retain, store, copy, and distribute the digital images. No one should back away from discussing these points.

The special collections being digitized are highly valued, unique works representing our culture and heritage, and our institutions have spent time and money acquiring, preserving, studying, and providing access to them. Of course, the tangible copies of the rare books and manuscripts are valuable, but their contents are valuable as well, and it is the contents that are being made available through digitization and electronic distribution. On this point, one should be clear and straightforward. Do not enter into any exclusive contract with a third party for digitization of special collections materials unless the institution will receive the digital files and other proprietary materials, such as subscriber lists if the digital copies are made available through fee-based or password-protected databases.

\section{Conclusion}

Whether or not to digitize special collections materials may seem like a no-win situation. If an institution proceeds, it runs the risk of making some mistakes and being criticized. If it waits to digitize, it runs the risk of losing third-party support 
for these expensive and labor-intensive projects. Do not let the details or fear of failure prevent you from moving forward. Opportunities abound. The same rationales that underlie building the vast and rich collections of rare books and manuscripts existing today apply to digitization and electronic access - the need to preserve rare and unique materials of cultural significance for posterity and to share these valuable works with others for the continued growth of learning and knowledge. If history is any indicator of the future, we will master the fine art of negotiations for digitization projects, and the rare books and manuscripts in our nation's libraries, archives, and museums will be available to the public via the Web. Personally and professionally, we should look forward to the challenges of these projects. We will realize many successes in the years to come.

\section{Author's Note}

During the plenary session of the RBMS Preconference from which this article was derived, I was honored to share the podium with Peter Hirtle, Technology Strategist and University Library IP Officer, Cornell University. Peter spoke about the Google Book Project. Our hope was that our combined presentations offered Preconference participants a view of what has happened with mass digitization projects - good and bad-and some practical advice about how to approach these opportunities in the future.

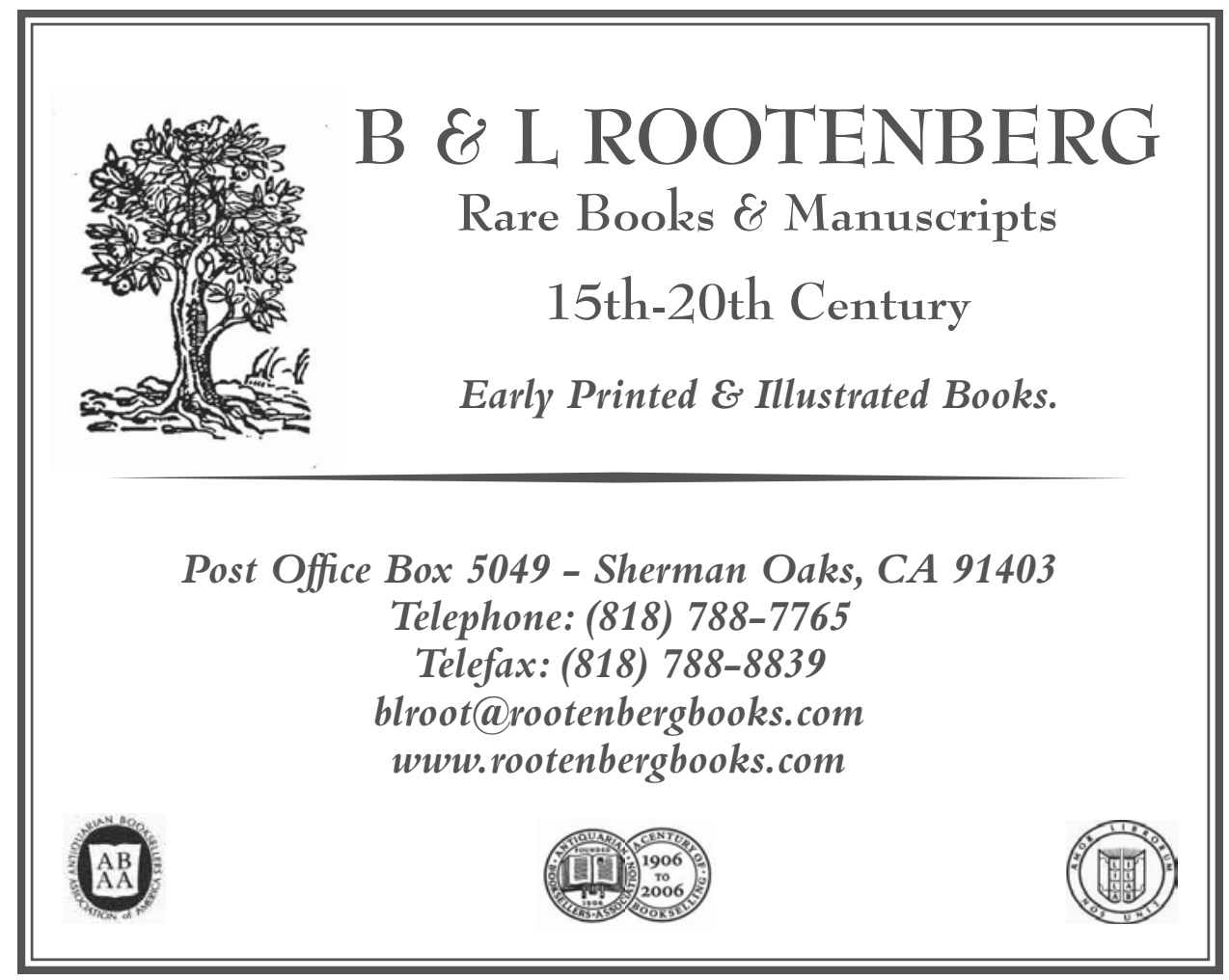

